\title{
Nucleolin promotes Ang II-induced phenotypic transformation of vascular smooth muscle cells via interaction with tropoelastin mRNA
}

\author{
LI FANG $^{1}$, PENG-FEI ZHANG ${ }^{2}$, KANG-KAI WANG ${ }^{3}$, ZHI-LIN XIAO $^{4}$, MEI YANG $^{4}$ and ZAI-XIN YU ${ }^{1}$ \\ ${ }^{1}$ Department of Cardiology, ${ }^{2}$ Key Laboratory of Cancer Proteomics of Chinese Ministry of Health, \\ Xiangya Hospital, Central South University; ${ }^{3}$ Department of Pathophysiology, Xiangya School of Medicine; \\ ${ }^{4}$ Department of Geriatric Cardiology, Xiangya Hospital, Central South University, Changsha, Hunan 410008, P.R. China
}

Received September 13, 2018; Accepted January 16, 2019

DOI: $10.3892 / \mathrm{ijmm} .2019 .4090$

\begin{abstract}
The current study aimed to clarify the role of nucleolin in the phenotypic transformation of vascular smooth muscle cells (VSMCs) and to preliminarily explore its underlying mechanism. The spatial and temporal expression patterns of nucleolin, and the effects of angiotensin II (Ang II) on the expression of VSMC phenotypic transformation markers, $\alpha$-smooth muscle-actin, calponin, smooth muscle protein $22 \alpha$ and osteopontin were investigated. The effects of nucleolin on VSMC phenotypic transformation and the expression of phenotypic transformation-associated genes, tropoelastin, epiregulin and fibroblast growth factor 2 (b-FGF), were determined. Protein-RNA co-immunoprecipitation was used to investigate the potential target genes regulated by the nucleolin in phenotypic transformation of VSMCs. Finally, the stability of tropoelastin mRNA and the effects of nucleolin on the expression of tropoelastin were assayed. The results revealed that Ang II significantly promoted the phenotypic transformation of VSMCs. The expression of nucleolin was gradually upregulated in VSMCs treated with Ang II at different concentrations for various durations. Ang II induced nucleolin translocation from the nucleus to cytoplasm. Additionally, Ang II significantly promoted the phenotypic transformation of VSMCs. Overexpression and silencing of nucleolin regulated the expressions of tropoelastin, epiregulin and b-FGF. There was an interaction between tropoelastin mRNA and nucleolin protein, promoting the stability of tropoelastin mRNA and enhancing the expression of tropoelastin at the protein level. Upregulation of nucleolin had an important role in Ang II-induced VSMC phenotypic transformation, and its underlying mechanism
\end{abstract}

Correspondence to: Professor Zai-Xin Yu, Department of Cardiology, Xiangya Hospital, Central South University, 87 Xiangya Road, Changsha, Hunan 410008, P.R. China

E-mail: yuzaixin@csu.edu.cn

Key words: nucleolin, angiotensin II, vascular smooth muscle cells, phenotypic transformation may be through interacting with tropoelastin mRNA, leading to its increased stability and protein expression. The findings provide a new perspective into the regulatory mechanism of VSMC phenotypic transformation.

\section{Introduction}

Proliferation of vascular smooth muscle cells (VSMCs) forms the common basis of the pathology of cardiovascular diseases, including hypertension, coronary artery disease and angiographic restenosis, and it has an important role in development of these diseases (1). Studies have demonstrated that phenotypic transformation of VSMCs is also pivotal for cardiovascular diseases $(2,3)$. When blood vessels are damaged or VSMCs cultured in vitro are stimulated by growth factors, VSMCs are rapidly transformed through phenotypic transformation, characterized by alteration of gene expressions. VSMCs are transformed from a contractile phenotype to a secretory phenotype (or dedifferentiated VSMCs) and acquire proliferation ability, and this process is termed phenotypic transformation (4). Therefore, how to control and reverse the phenotypic transformation of VSMCs is the key measure to control the abnormal proliferation of VSMCs. No methods or drugs are particularly effective in preventing the phenotypic transformation of VSMCs. Generally, it is hypothesized that endogenous active substances in the body have a spontaneous regulatory role in the proliferation or phenotypic transformation of VSMCs; thus, it is important to identify novel endogenous regulatory proteins mediating the phenotype of VSMCs. Nucleolin is the most abundant RNA-binding protein in the nucleolus. Its major functions are binding and transporting ribosomal RNAs, and regulating the assembly of ribosomes $(5,6)$. Previous studies have demonstrated that nucleolin is involved in cell growth, proliferation, apoptosis, inflammation, immune and other physiological and pathological processes (7-9). Nucleolin consists of three major functional domains: Amino terminus, central region and carboxyl terminus. The central region is composed of four conserved and consistent RNA binding domains [RBDs; consensus sequence type RBD (CS-RBD)]. Currently, it is hypothesized that the nuclear localization signals of nucleolin 
$\mathrm{N}$-terminal, the central area of the RBD and the C-terminal glycine rich region determine the nucleolar localization of nucleolin, and are also required for the bidirectional shift of the protein between the cytoplasm and nucleus (10). The cellular shuttle function of nucleolin is involved in the regulation of cell proliferation, growth, apoptosis and other biological processes. It remains unknown whether nucleolin regulates VSMC phenotypic transformation and its underlying mechanism. A large number of studies have revealed that the RNA binding properties nucleolin of are important for a variety of biological functions, and the specific nucleic acid binding element is '(T/G) CCCG (A/G)' (11-16). Nucleolin shuttles between the nucleus and cytoplasm in different types of cells and under different stimulation. In the majority of cells, nucleolin is mainly expressed in the nucleus and can also be present in the cell membrane or cytoplasm, as glycosylated or phosphorylated forms $(17,18)$. All of these findings indicate that nucleolin has an important role in regulating cell proliferation, growth, phenotypic transformation and apoptosis, and the cellular shuttle function of nucleolin participates in various biological processes.

In the present study, it was aimed to investigate the role of nucleolin in the transformation from a contractile phenotype to a secretory phenotype, and to investigate the endogenous active substances mediating VSMC phenotypic transformation. Angiotensin II (Ang II) was used to induce the phenotypic transformation of VSMCs. Gene overexpression and RNA interference techniques were used to assess the effect of cellular nucleolin on Ang II-mediated VSMC phenotypic transformation and its influence on the expressions of VSMC phenotypic transformation-associated genes. Furthermore, the spatial and temporal expression patterns of nucleolin in VSMCs were also investigated. Protein-RNA co-immunoprecipitation was used to investigate the possible target genes regulated by nucleolin in phenotypic transformation of VSMCs. Finally, the decay of target gene mRNA and the effect of nucleolin on the expression of target gene at the protein level were assayed. The findings provide a new perspective on the regulatory mechanism of VSMC phenotypic transformation.

\section{Materials and methods}

Cell culture and treatment. Rat VSMCs were obtained from Shanghai Tiancheng Life Technologies (Shanghai, China; American Type Culture Collection ${ }^{\circledR}$ no. CRL-1476) and maintained in Dulbecco's modified Eagle's medium supplemented with $10 \%$ heat-inactivated fetal bovine serum, $2 \mathrm{mM}$ glutamine and antibiotic-antimycotic mix in a humidified incubator with $5 \% \mathrm{CO}_{2}$ and $95 \%$ air at $37^{\circ} \mathrm{C}$. VSMCs were stimulated with Ang II at different concentrations $\left(10^{-5}, 10^{-6}, 10^{-7}\right.$ and $10^{-8} \mathrm{mmol} / \mathrm{l}$ ) for $48 \mathrm{~h}$ or $10^{-5} \mathrm{mmol} / \mathrm{l} \mathrm{Ang} \mathrm{II} \mathrm{for} \mathrm{different} \mathrm{dura-}$ tions (19). Cell viabilities were analyzed using the MTT method. Briefly, VSMCs were seeded into 96-well microtiter plates at a density of $2 \times 10^{4}$ cells/well in $200 \mu \mathrm{l}$ culture medium. The VSMCs were treated with different concentrations for various durations. Subsequently, $100 \mu 1$ MTT solution $(5 \mathrm{mg} / \mathrm{ml})$ was added to each well, and the cells were incubated for $4 \mathrm{~h}$ at $37^{\circ} \mathrm{C}$, followed by addition of $150 \mu \mathrm{l}$ dimethyl sulfoxide into each well. The absorbance was measured at $570 \mathrm{~nm}$, and the values were used to calculate the relative ratio of viable cells to total cells.

Extraction of cytoplasmic and nuclear proteins. The cell membrane, cytoplasmic and nuclear protein fractions were collected and stored at $-70^{\circ} \mathrm{C}$ using the NE-PER ${ }^{\mathrm{TM}}$ nuclear and cytoplasmic extraction regent kit (Pierce; Thermo Fisher Scientific, Inc., Waltham, MA, USA).

Extraction of total cell proteins. Following the corresponding treatments, VSMCs were washed with pre-cooled PBS three times. According to the cell confluence, 50-80 $\mu 1$ 12X SDS lysis buffer (100 mM Tris- $\mathrm{HCl}, 200 \mathrm{mM}$ dithiothreitol, $40 \mathrm{~g} / 1 \mathrm{SDS}, 20 \%$ glycerol; pH 6.8) was added to each well. Subsequently, the cell fragments and lysates were transferred into the $1.5 \mathrm{ml}$ centrifuge tubes, denatured at $100^{\circ} \mathrm{C}$ for $10 \mathrm{~min}$ and then centrifuged at $12,000 \mathrm{x}$ g for $10 \mathrm{~min}$ at $4^{\circ} \mathrm{C}$. The supernatant was transferred to $0.5 \mathrm{ml}$ centrifuge tubes and stored at $-70^{\circ} \mathrm{C}$. The protein concentration was determined using a Bicinchoninic Acid Protein Assay kit (Beyotime Institute of Biotechnology, Haimen, China) according to the manufacturer's instructions.

Reverse transcription-quantitative polymerase chain reaction $(R T-q P C R)$ analysis. Total RNA was extracted using the RNeasy kit (Qiagen, Inc., Valencia, CA, USA) according to the manufacturer's instructions, and $2 \mu \mathrm{g}$ purified RNA was reverse transcribed into cDNA $\left(37^{\circ} \mathrm{C}\right.$ for $15 \mathrm{~min}$, followed by $85^{\circ} \mathrm{C}$ for $5 \mathrm{sec}$ using RT kit; Fermentas; Thermo Fisher Scientific, Inc.). The expressions of target genes were examined using the 7500 Fast Real-Time PCR system (Applied Biosystems; Thermo Fisher Scientific, Inc.) using a QuantiTect SYBR-Green PCR kit (Qiagen, Inc.). Briefly, after an initial denaturation step at $95^{\circ} \mathrm{C}$ for $10 \mathrm{sec}$, amplifications were performed for 40 cycles at a melting temperature of $95^{\circ} \mathrm{C}$ for $5 \mathrm{sec}$ and an annealing temperature of $60^{\circ} \mathrm{C}$ for $30 \mathrm{sec}$ and extension at $72^{\circ} \mathrm{C}$ for $30 \mathrm{sec}$. Primer sequences used in the present study are listed in Table I. PCR products were detected by $1.5 \%$ agarose gel electrophoresis, stained with ethidium bromide and imaged on a UV transilluminator. The relative expressions of target genes were calculated by $2^{-\Delta \Delta \mathrm{Cq}}$ method (20), and $\beta$-actin was selected as the reference gene. Each experiment was conducted in triplicate.

Amplification and extraction of recombinant plasmids. The recombinant plasmids pcDNA3.1-Nuc and PsiRNA-Nuc were kindly gifted by Professor Kangkai Wang (Department of Pathophysiology, Xiangya School of Medicine, Central South University, Changsha, China). The recombinant vector PsiRNA-Nuc containing the nucleolin small interfering RNA (siRNA) was constructed. Using nucleolin as the target, the siRNA sequences were as follows: Nucleolin siRNA, 5'-ACC TGCCTTCGCGAGCTTCACCAT-3'; the scramble siRNA, 5'-CATGGTGAAGCTCGCGAAGGCAGGT-3'. Nucleolin expression plasmid (pcDNA3.1-Nuc) and RNA interference fragment of nucleolin (PsiRNA-Nuc) were transformed into competent cells, and then monoclonal colonies were inoculated into $5 \mathrm{ml} \mathrm{LB}$ medium containing corresponding antibiotics and maintained at $37^{\circ} \mathrm{C}$ on a rotary bed $(250 \mathrm{rpm})$ overnight. Subsequently, the culture suspension was transferred to 
Table I. Primer sequences used in the present study.

Genes

$\alpha$-smooth muscle-actin

Calponin

Smooth muscle protein $22 \alpha$

Osteopontin

$\beta$-actin

Nucleolin

Epiregulin

Fibroblast growth factor 2

Tropoelastin
Primer sequences

Forward: 5'-ACTGGGACGACATGGAAAAG-3'

Reverse: 5'-CATCTCCAGAGTCCAGCACA-3'

Forward: 5'-ACTTCATGGATGGCCTCAAG

Reverse: 5'-GTGCCAGTTCTGGGTTGACT

Forward: 5'-TTCTGCCTCAACATGGCCAAC-3'

Reverse: 5'-CACCTTCACTGGCTTGGATC-3

Forward: 5'-ATGGCTTTCATTGGAGTTGC-3'

Reverse: 5'-CCTCGCCTTTGCCGATCC-3'

Forward: 5'-CCTCGCCTTTGCCGATCC-3'

Reverse: 5'-GGATCTTCATGAGGTAGTCAGTC-3'

Forward: 5'-CAATCAGGCTGGAGTTGCAAG-3'

Reverse: 5'-TGGCCCAGTCCAAGGTAACTT-3'

Forward: 5'-GTGTCAATAACAAAGTGTAGC-3'

Reverse: 5'-ATTACAGAAAGAAGTGTTCACATCG-3'

Forward: 5'-GCAGAAGAGAGAGGAGTGTGT-3'

Reverse: 5'-CCCAGTTCGTTTCAGTGC-3'

Forward: 5'-ATGATCCCAGGTGTTGGGGGC-3'

Reverse: 5'-TCCAAGATCACCA GGTACAAGG-3'
$200 \mathrm{ml}$ LB medium containing the corresponding antibiotics. When the turbidity reached the standard, the bacteria were collected for the extraction of plasmids. PsiRNA-Nuc and pcDNA3.1-Nuc were extracted using a QIAGEN Plasmid Maxi kit (Qiagen, Inc.) according to the manufacturer's instructions, and the DNA concentration of purified plasmids was determined using spectrophotometer. Finally, isolated plasmids were stored at $-70^{\circ} \mathrm{C}$.

Transient transfection. Transfection of cells was performed using MegaTran 1.0 following the manufacturer's instructions (OriGene Technologies, Inc., Rockville, MD, USA). Briefly, $5 \times 10^{5}$ cells were cultured in $5 \mathrm{ml}$ appropriate complete growth medium at $37^{\circ} \mathrm{C}$ in a $\mathrm{CO}_{2}$ incubator until the cells reached $70-80 \%$ confluence $(24 \mathrm{~h})$. Subsequently, cells were washed with serum-free and antibiotic-free medium and transfected with pcDNA3.1-Nuc/PsiRNA-Nuc (experimental) or pcDNA3.1/PsiRNA (vector control) by mixing $6 \mu 1$ MegaTran1.0 containing $2 \mu \mathrm{g}$ DNA, and the mixture was placed at room temperature for $\sim 10 \mathrm{~min}$. Subsequently, the mixture was added to 6-well plate, followed by gentle agitation and incubation at $37^{\circ} \mathrm{C}$ for $24 \mathrm{~h}$ in a $\mathrm{CO}_{2}$ incubator.

Western blot analysis. Following various treatments, VSMCs cells were lysed with radioimmunoprecipitation assay lysis buffer (Shanghai Biyuntian Biotechnology, Ltd., Shanghai, China). The protein concentration was measured using a Bicinchoninic Acid Protein Assay kit (Beyotime Institute of Biotechnology). Equal amounts of proteins (20 $\mu \mathrm{g} / \mathrm{lane})$ were subjected to SDS-PAGE using $10 \%$ gels and transferred onto polyvinylidene fluoride membranes. The membrane was blocked with Tris-buffered saline-Tween containing 5\% bovine serum albumin (BSA; Gibco; Thermo Fisher Scientific, Inc.) by incubating at room temperature for $6 \mathrm{~h}$. Following removal of the blocking solution, the blots were incubated with respective primary antibodies against nucleolin $(1: 1,000$; cat. no. N2662; rabbit polyclonal antibody; Sigma-Aldrich; Merck KGaA, Darmstadt, Germany), $\alpha$-smooth muscle-actin ( $\alpha$-SM-actin; 1:500; cat. no. BM0002; mouse monoclonal antibody; Wuhan Boster Biological Technology, Ltd, Wuhan, China), smooth muscle protein $22 \alpha$ (1:1,000; cat. no. ab14106; SM22a; rabbit polyclonal antibody; Abcam, Cambridge, UK), calponin (1:1,000; cat. no. ab700; mouse monoclonal antibody; Abcam), osteopontin (OPN; 1:1,000; cat. no. c-21742; mouse monoclonal antibody; Santa Cruz Biotechnology, Inc., Dallas, TX, USA), tropoelastin (1:1,000; cat. no. ab21600; rabbit polyclonal antibody; Abcam), $\beta$-actin (1:1,000; cat. no. ab49900; mouse monoclonal antibody; Abcam), $\beta$-tubulin $(1: 1,000$; cat. no. ab18207; rabbit polyclonal antibody; Abcam), and proliferating cell nuclear antigen (PCNA; 1:1,000; cat. no. 610664; mouse monoclonal antibody; BD Biosciences, San Jose, CA, USA) at $25^{\circ} \mathrm{C}$ for $2 \mathrm{~h}$. Subsequently, blots were incubated with peroxidase-conjugated goat anti-rabbit $(1: 5,000$; cat. no. sc-2004) or anti-mouse IgG (1:5,000; cat.no. sc-516180) secondary antibody (Santa Cruz Biotechnology, Inc.) for $1 \mathrm{~h}$ at $37^{\circ} \mathrm{C}$. Immunoreactive bands were visualized using an Enhanced Chemiluminescence Detection kit (Beyotime Institute of Biotechnology) according to the manufacturer's instructions, and the densitometry analysis was performed using ImageJ (1.48v) software (National Institutes of Health, Bethesda, MD, USA).

Immunocytochemical analysis. VSMCs were seeded into 6 -well plates with sterile coverslips at $80 \%$ confluence, fixed in 
$4 \%$ formaldehyde at room temperature for $20 \mathrm{~min}$ and permeabilized with $0.1 \%$ Triton $\mathrm{X}-100$ at $4^{\circ} \mathrm{C}$ for $10 \mathrm{~min}$. Coverslips were blocked with $2 \%$ BSA (Sigma-Aldrich; Merck KGaA) at room temperature for $1 \mathrm{~h}$ and processed for immunofluorescence staining with rabbit anti-nucleolin polyclonal antibody (1:100; cat. no. N2662; Sigma-Aldrich; Merck KGaA), followed by incubation with fluorescein isothiocyanate-conjugated sheep anti-rabbit IgG (1:500; cat. no. BA1105; Wuhan Boster Biological Technology, Ltd.). Nuclear morphology was analyzed with $0.5 \mu \mathrm{g} / \mathrm{ml}$ Hoechst 33258 staining at room temperature for $20 \mathrm{~min}$. Between all incubation steps, cells were washed with PBS containing $0.2 \%$ BSA three times (3 min for each). Images were acquired using a fluorescence microscope (ECLIPSE 80i; Nikon Corporation, Tokyo, Japan).

Bioinformatics analysis identification of nucleolin binding elements. The mRNA sequences of 12 vascular smooth muscle cell phenotype-associated genes, such as epiregulin, were searched in PubMed (ncbi.nlm.nih.gov/pubmed/) and UCSC Genome Browser gene databases (genome.ucsc.edu/), and the mRNA sequences of these genes were screened for nucleolin binding elements, such as '(T/G) CCCG (A/G)' and analysed whether these binding elements were located in the 5' untranslated region (UTR), 3' UTR or coding region.

Co-immunoprecipitation of nucleolin protein and tropoelastin $m R N A$. Following treatment, VSMCs were homogenized in $1 \mathrm{ml}$ radioimmunoprecipitation assay lysis buffer (Shanghai Biyuntian Biotechnology, Ltd.) containing a variety of protease inhibitor mixtures (10 $\mu \mathrm{l} / 0.1 \mathrm{~g}$ tissue weight; Sigma-Aldrich; Merck KGaA). Soluble proteins were collected following centrifugation at $12,000 \mathrm{x}$ g for $15 \mathrm{~min}$ at $4^{\circ} \mathrm{C}$. Following quantitative analysis by using a bicinchoninic acid assay, protein supernatant (500 $\mu \mathrm{l}$ each) was divided into three equal fractions as follows: Input sample; control IgG for immunoprecipitation; and the antibody against nucleolin monoclonal antibody. An aliquot $(500 \mu \mathrm{l})$ of cell lysate was pre-cleared by incubation with $200 \mu \mathrm{l}$ protein $\mathrm{A} / \mathrm{G}$ beads on ice for $60 \mathrm{~min}$, followed by centrifugation at $12,000 \mathrm{x}$ g for $10 \mathrm{~min}$ at $4^{\circ} \mathrm{C}$. Then, $15 \mu \mathrm{g}$ anti-nucleolin monoclonal antibody $(1: 1,000$; cat. no. sc-8031; Santa Cruz Biotechnology, Inc.) was added to the pre-cleared cell lysate, and the mixture was incubated at $4^{\circ} \mathrm{C}$ for $1 \mathrm{~h}$, followed by the addition of $200 \mu \mathrm{l}$ protein $\mathrm{A} / \mathrm{G}$ beads. The lysate was incubated at $4^{\circ} \mathrm{C}$ with shaking, and the immune complexes were separated by centrifugation at $10,000 \mathrm{x} \mathrm{g}$ for $30 \mathrm{sec}$ at $4^{\circ} \mathrm{C}$. RNA was extracted from the immunoprecipitate, and cDNA was prepared using a reverse transcription kit (Fermentas; Thermo Fisher Scientific, Inc.) and subjected to PCR (as described). Western blot analysis was performed using the other half of the precipitate to detect the content of nucleolin in the cell extracts and the sediments, which confirmed the effectiveness of the nucleolin antibody.

Measurement of tropoelastin mRNA stability. VSMCs were treated with either $10^{-6} \mathrm{mM}$ Ang II for $48 \mathrm{~h}$ or nucleolin siRNA plasmid/pcDNA3.1-Nuc plasmid for the indicated periods, and the cells were then incubated with either $0.5 \%$ ethanol or $5 \mu \mathrm{g} / \mathrm{ml}$ actinomycin $\mathrm{D}$ in $0.5 \%$ ethanol. Aliquots were removed from the cultures at $30 \mathrm{~min}$ intervals over a 3-h time course. Actinomycin D at this concentration induced no DNA fragmentation during this period. At the indicated time points, $2 \times 10^{5}$ cells were harvested, and total RNA was isolated using the RNeasy kit (Qiagen, Inc.). RT-qPCR amplification of the pooled cDNA was performed as described.

Statistical analysis. Data are expressed as the mean \pm standard error based on at least three independent experiments. Statistical analysis was performed by one-way analysis of variance for multiple testing, followed by post hoc testing (least significant difference test). $\mathrm{P}<0.05$ was considered to indicate a as statistically significant difference.

\section{Results}

Effect of Ang II on phenotypic transformation of VSMCs. RT-qPCR revealed that the mRNA expression levels of contractive phenotypic markers $\alpha$-SM-actin, calponin and SM22a, and synthetic phenotypic marker, OPN, were negatively and positively associated with the Ang II concentration, respectively, and the most evident effect was observed when VSMCs were treated with Ang II at $10^{-5} \mathrm{mmol} / 1$ for $48 \mathrm{~h}$ (Fig. 1A). Additionally, the mRNA expressions of $\alpha$-SM-actin, calponin and SM22a, and OPN were negatively and positively associated with the duration of Ang II induction, respectively, and the most evident effect was observed when VSMCs were treated with $10^{-5} \mathrm{mmol} / \mathrm{l}$ Ang II for $72 \mathrm{~h}$ (Fig. 1B). Similarly, western blotting demonstrated that the protein expression of $\alpha$-SM-actin, calponin and SM22a, and OPN was negatively and positively correlated with the Ang II concentration, respectively, and the most evident effect was observed when VSMCs were treated with Ang II at $10^{-5} \mathrm{mmol} / 1$ for $48 \mathrm{~h}$ (Fig. 1C). In addition, the protein expression of $\alpha$-SM-actin, calponin and SM22a, and OPN was negatively and positively correlated with the duration of Ang II induction, respectively, and the most evident effect was observed when VSMCs were treated with $10^{-5} \mathrm{mmol} / \mathrm{l}$ Ang II for $72 \mathrm{~h}$ (Fig. 1D). These results suggested that Ang II significantly promoted the phenotypic transformation of VSMCs. Dose-response analysis of VSMCs treated with various concentrations of Ang II and time-response analysis of VSMCs treated with Ang II for 0-72 $\mathrm{h}$ demonstrated that the proliferation of VSMCs was increased in a dose- and time-dependent manner (Fig. 1E). It indicated that Ang II had no obvious cytotoxic effect on cell viabilities of VSMCs, and therefore the cytotoxicity of Ang II at experimental doses could be excluded in this study.

Effect of Ang II on the expression and subcellular localization of nucleolin in VSMCs. The mRNA expression of nucleolin in VSMCs was increased by Ang II treatment at different concentrations for $48 \mathrm{~h}$, and the most evident effect was observed when VSMCs were treated with $10^{-6} \mathrm{mmol} / \mathrm{l}$ Ang II for $48 \mathrm{~h}$, with an increase of up to 4.26-fold compared with the normal level. The mRNA expression of nucleolin in VSMCs was increased by treatment with $10^{-6} \mathrm{mmol} / 1 \mathrm{Ang}$ II for different durations, and the most evident effect was observed at $48 \mathrm{~h}$ (Fig. 2A). Similarly, the protein expression of nucleolin was gradually increased by treatment with Ang II at different concentrations for $48 \mathrm{~h}$, and the most evident effect was observed when VSMCs were treated with $10^{-6} \mathrm{mmol} / \mathrm{l}$ Ang II for $48 \mathrm{~h}$, exhibiting an increase of up to 3.86-fold compared 

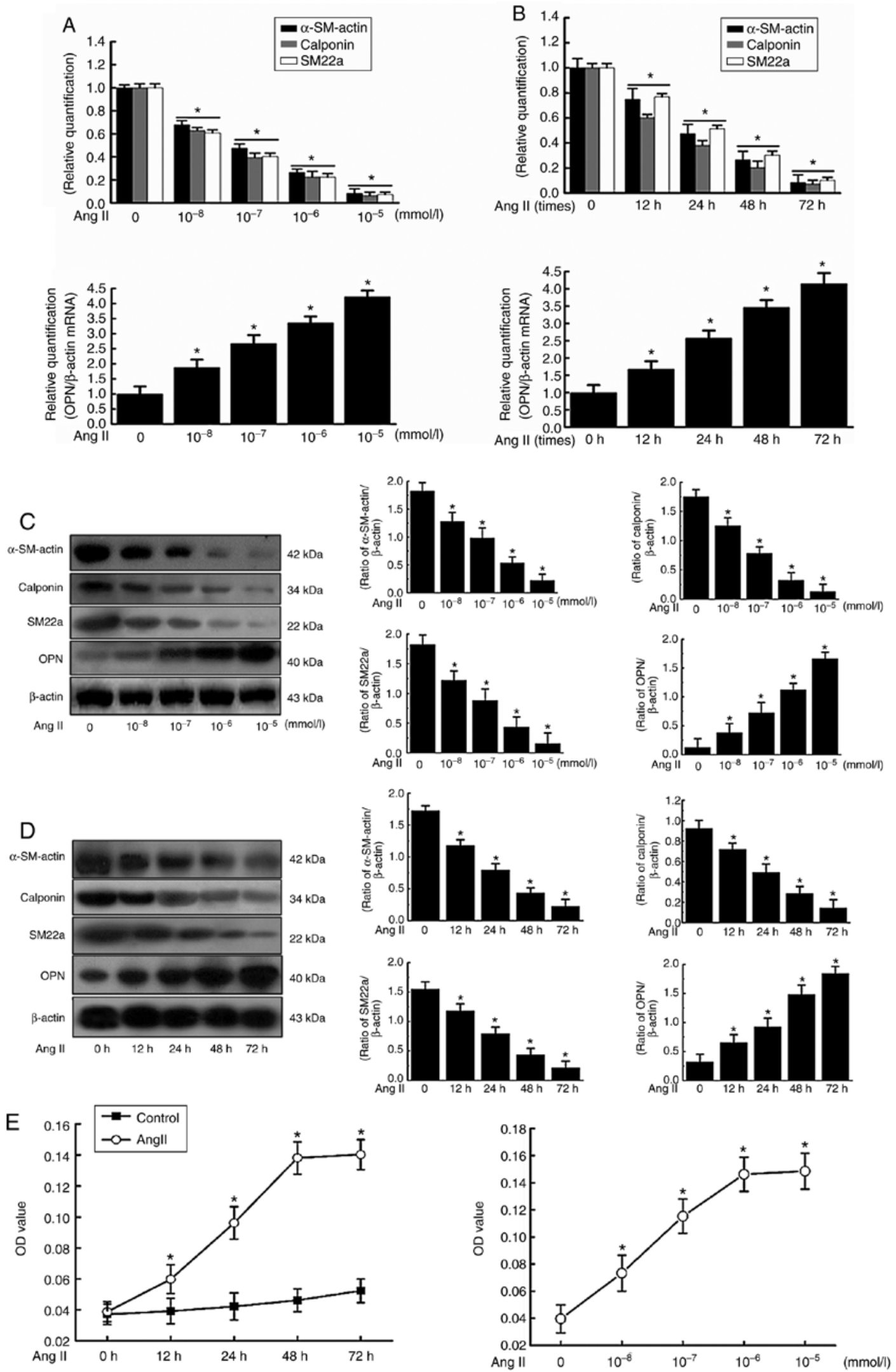

Figure 1. Effect of Ang II on the expressions of VSMC phenotypic transformation markers $\alpha$-SM-actin and OPN. VSMCs were stimulated with (A) different concentrations of Ang II for $48 \mathrm{~h}$ and (B) Ang II $\left(10^{-5} \mathrm{mmol} / \mathrm{l}\right)$ for different durations; reverse transcription-quantitative polymerase chain reaction was used to detect the expressions of contractile phenotype of VSMCs ( $\alpha$-SM-actin, calponin, SM22a) and synthetic phenotype of VSMCs OPN at the mRNA level. VSMCs were stimulated with (C) different concentrations of Ang II for $48 \mathrm{~h}$ and (D) Ang II ( $\left.10^{-5} \mathrm{mmol} / \mathrm{l}\right)$ for different durations; the total protein was extracted, and the expressions of contractile phenotype of VSMCs ( $\alpha$-SM-actin, calponin, SM22a) and synthetic phenotype of VSMCs OPN at the protein level were analyzed by western blotting. (E) Dose-response study of VSMCs treated with Ang II of various concentrations and time-response study of VSMCs treated with Ang II for 0-72 h showed that there was a dose and time-dependent increase in the proliferation of VSMCs. Data are expressed as the mean \pm standard error. "P $<0.05$ vs. control. VSMCs, vascular smooth muscle cells; Ang II, angiotensin II; $\alpha$-SM-actin, $\alpha$-smooth muscle-actin; SM22a, smooth muscle protein $22 \alpha$; OPN, osteopontin; OD, optical density. 
A
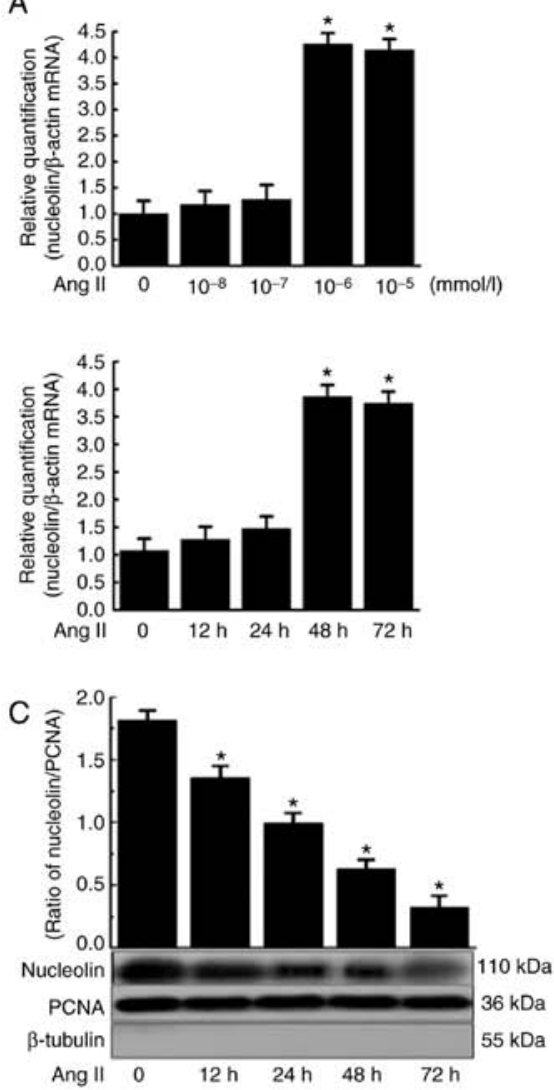

B
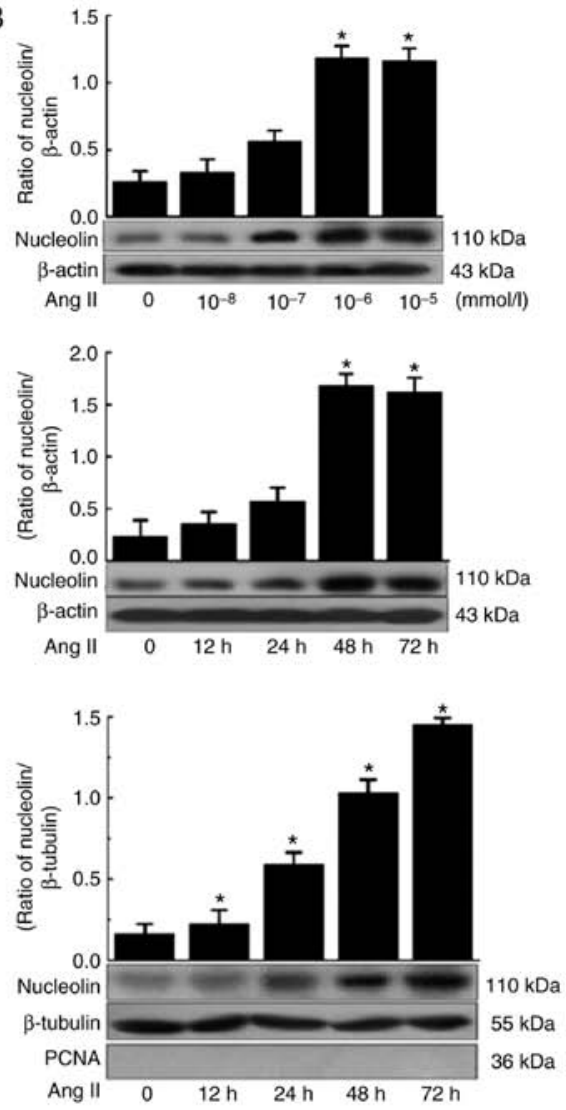

D
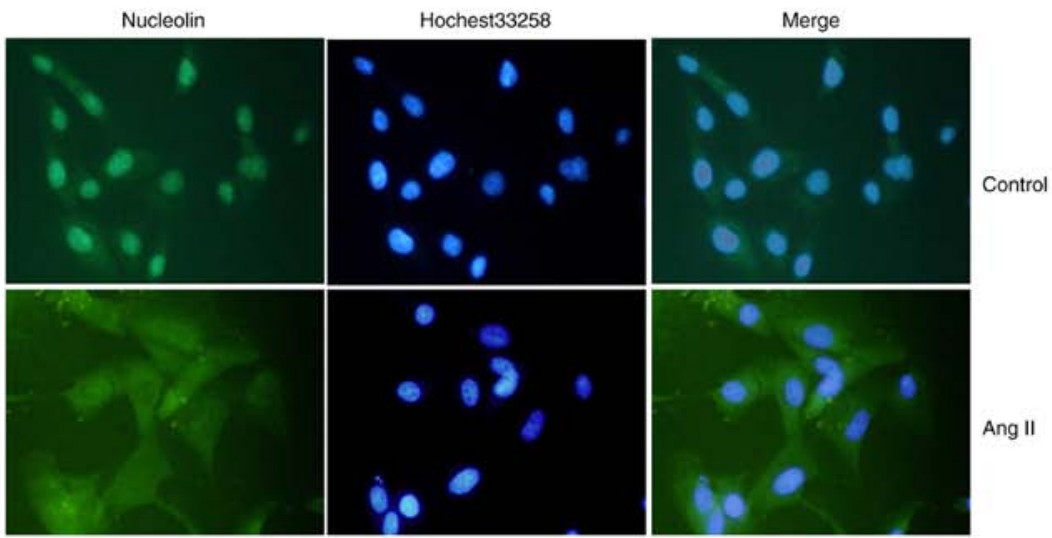

Figure 2. Effect of Ang II on the expression and subcellular localization of nucleolin in VSMCs. (A) VSMCs were stimulated with different concentrations of Ang II for different durations, the total RNA of cells was extracted, and cDNA was obtained after reverse transcription. Quantitative polymerase chain reaction was used to detect the expression of nucleolin. ${ }^{*} \mathrm{P}<0.05$ vs. control group $\left(0,10^{-8}\right.$ and $\left.10^{-7} \mathrm{mmol} / \mathrm{l}\right)$. (B) VSMCs were stimulated with different concentrations of Ang II for different durations, the total protein was extracted, and the expression of nucleolin was analyzed by western blotting. " $\mathrm{P}<0.05 \mathrm{vs.}$. control group $\left(0,10^{-8}\right.$ and $\left.10^{-7} \mathrm{mmol} / \mathrm{l}\right)$. (C) VSMCs were stimulated with Ang II $\left(10^{-6} \mathrm{mmol} / \mathrm{l}\right)$ for $12,24,48$ and $72 \mathrm{~h}$, nuclear protein and cytoplasmic protein were extracted, western blotting was used to detect the expression of nucleolin, and $\beta$-tubulin and PCNA were used as the internal controls of cytoplasmic protein and nuclear protein, respectively. Data are expressed as the mean \pm standard error, $n=5$. (D) VSMCs were stimulated with Ang II $\left(10^{-6} \mathrm{mmol} / \mathrm{l}\right)$ for $48 \mathrm{~h}$, and indirect immunofluorescence was used to observe the subcellular localization of nucleolin. Nucleolin, analysis of nucleolin with fluorescein isothiocyanate-labeled antibody (green); Hochest33258, nuclei were counterstained with Hoechst 33258 (violet); Merge, overlap of cytoplasmic and nuclear fractions. Magnification, x400. VSMCs, vascular smooth muscle cells; Ang II, angiotensin II; PCNA, proliferating cell nuclear antigen.

with the normal level. The protein expression of nucleolin was increased by treatment with $10^{-6} \mathrm{mmol} / \mathrm{l}$ Ang II for different durations, the most evident effect was observed at $48 \mathrm{~h}$, and such an effect lasted to $72 \mathrm{~h}$ (Fig. 2B).

Nucleolin was predominantly localized in the nucleus of VSMCs under normal conditions, and only a small portion was present in the cytoplasm. However, it was translocated from the nuclear to cytoplasm following Ang II-induced phenotypic transformation, exhibiting increased content of nucleolin in the cytoplasm and gradually decreased content of nucleolin in the nucleus (Fig. 2C). In addition, $\beta$-tubulin and PCNA were used as the internal controls for cytoplasmic protein and nuclear protein, respectively, indicating no obvious contamination between the components. The aforementioned results were further confirmed by indirect immunofluorescence analysis. In the control cells, the majority of the nucleolin (green fluorescence) was localized in the nucleus, while only a small portion was present in the cytoplasm. However, the expression 

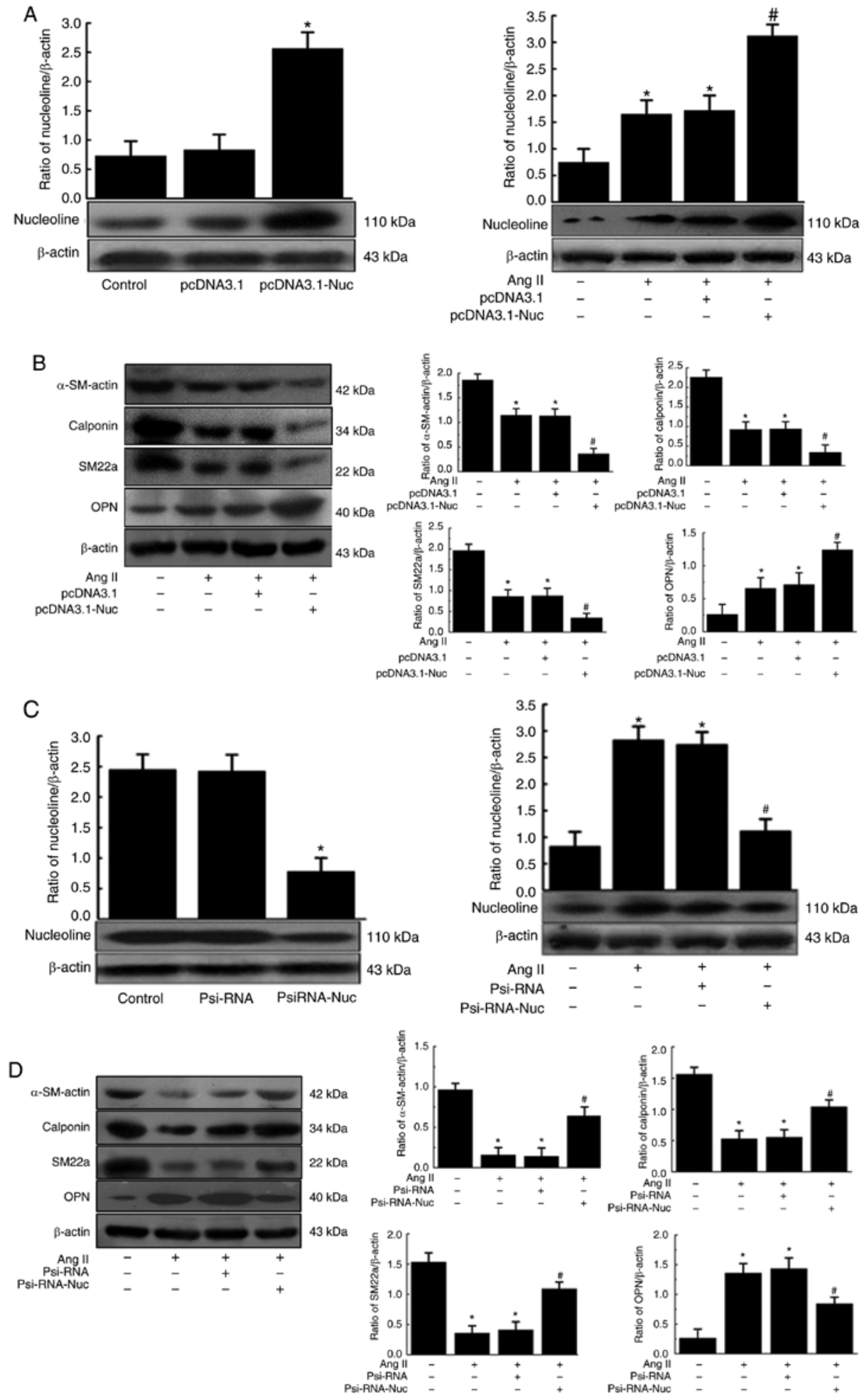

Figure 3. Effect of nucleolin overexpression and silencing on Ang II-induced phenotypic transformation of VSMCs. (A) Top panel, effect of nucleolin overexpression on the expression of nucleolin in VSMCs; VSMCs were transfected with the control plasmid (pcDNA3.1) and the recombinant plasmid pcDNA3.1-Nuc; total protein was extracted from the transfected cells and western blotting was performed (data are expressed as the mean \pm standard error, $\mathrm{n}=5 ;{ }^{*} \mathrm{P}<0.05$ vs. control and pcDNA3.1 group). Bottom panel, effect of nucleolin overexpression on Ang II-induced expression of nucleolin in VSMCs; VSMCs were transfected with pcDNA3.1 and pcDNA3.1-Nuc, and then cells were treated with $10^{-6} \mathrm{mmol} / \mathrm{l} \mathrm{Ang} \mathrm{II} \mathrm{for} 48 \mathrm{~h}$. (B) Effect of nucleolin overexpression on Ang II-induced expressions of VSMC phenotypic transformation markers $\alpha$-SM-actin, calponin, SM22a and OPN. VSMCs were transfected with pcDNA3.1 and pcDNA3.1-Nuc, and then cells were treated with $10^{-6} \mathrm{mmol} / 1$ Ang II for $48 \mathrm{~h}$. (C) Left panel, effect of silencing of nucleolin on expression of nucleolin in VSMCs. VSMCs were transfected with the control plasmid (PsiRNA) and nucleolin siRNA plasmid (PsiRNA-Nuc); total protein was extracted from the transfected cells, and then western blotting was performed. Right panel, effect of silencing of nucleolin on Ang II-induced expression of nucleolin in VSMCs. VSMCs were transfected with PsiRNA and PsiRNA-Nuc, and then cells were treated with $10^{-6} \mathrm{mmol} / \mathrm{l}$ Ang II for $48 \mathrm{~h}$. (D) Effect of silencing of nucleolin on Ang II-induced expressions of VSMC phenotypic transformation markers $\alpha$-SM-actin, calponin, SM22a and OPN. VSMCs were transfected with PsiRNA and PsiRNA-Nuc, and then cells were treated with $10^{-6} \mathrm{mmol} / 1 \mathrm{Ang}$ II for $48 \mathrm{~h}$ (data are expressed as the mean \pm standard error, $\mathrm{n}=5$; ${ }^{*} \mathrm{P}<0.05 \mathrm{vs}$. normal control group; " $\mathrm{P}<0.05$ vs. untransfected cell group and pcDNA3.1 or PsiRNA group). VSMCs, vascular smooth muscle cells; control, untransfected cell group; Ang II, angiotensin II treatment; pcDNA3.1, control plasmid group; pcDNA3.1-Nuc, nucleolin overexpression plasmid; OPN, osteopontin; $\alpha$-SM-actin, $\alpha$-smooth muscle-actin; SM22a, smooth muscle protein 22 $\alpha$; PsiRNA, control plasmid group; PsiRNA-Nuc, nucleolin RNA interference plasmid. 
Table II. Bioinformatics analysis identification of 12 phenotypic transformation-associated genes (mRNA) containing nucleolin binding elements.

\begin{tabular}{lllc}
\hline Gene & Nucleolin-binding element & \multicolumn{1}{c}{ Site } & Number \\
\hline Epiregulin & GCCCGG & 3' UTR & 1 \\
Tropoelastin & (T/G)CCCG(A/G) & Coding region & 5 \\
Thrombospondin & GCCCGG & Coding region & 1 \\
Epidermal growth factor & TCCCGG/GCCCGG & $5^{\prime}$ UTR and coding region & 2 \\
Fibroblast growth factor 2 & TCCCGG/GCCCGG & $5^{\prime}$ UTR & 2 \\
Platelet derived growth factor-BB & GCCCGG & 5' UTR & 2 \\
Matrix metallopeptidase 1 & GCCCGG & Coding region & 1 \\
Insulin-like growth factor 1 & TCCCGA & Coding region & 1 \\
P38 mitogen activated protein kinase & GCCCGA/GCCCGG & 5' UTR, coding region, 3' UTR & 3 \\
Nuclear factor-kB & TCCCGA & Coding region & 1 \\
Angiotensin II & TCCCGG & Coding region & 1 \\
Tumor necrosis factor- $\alpha$ & GCCCGA/TCCCGG & $5^{\prime}$ UTR and 3' UTR & 2 \\
\hline
\end{tabular}

UTR, untranslated region.

of nucleolin was increased in the cytoplasm, while its expression was decreased in the nucleus following the treatment of VSMCs with $10^{-6} \mathrm{mmol} / \mathrm{l}$ Ang II for $48 \mathrm{~h}$ (Fig. 2D). These findings suggested that Ang II induces nucleolin translocation from the nucleus to cytoplasm.

Effect of nucleolin overexpression and silencing on Ang II-induced phenotypic transformation of VSMCs. Results demonstrated that nucleolin was overexpressed in pcDNA3.1-Nuc-transfected cells compared with the control plasmid pcDNA3.1 and untransfected group cells. Furthermore, the expression of nucleolin at the protein level was significantly increased in the untransfected and control plasmid groups following $10^{-6} \mathrm{mmol} / 1$ Ang II stimulation for $48 \mathrm{~h}$, while the nucleolin overexpression further increased the Ang II-induced expression of nucleolin (Fig. 3A). Additionally, western blot analysis demonstrated that the expression of OPN was significantly increased in the untransfected and control plasmid groups by Ang II stimulation, while nucleolin overexpression further increased the Ang II-induced expression of OPN. By contrast, the protein expressions of $\alpha$-SM-actin, calponin and SM22a were significantly decreased by Ang II stimulation of untransfected and control plasmid groups, while nucleolin overexpression further decreased the Ang II-induced expressions of $\alpha$-SM-actin, calponin and SM22a (Fig. 3B).

The expression of nucleolin was significantly inhibited in PsiRNA-Nuc-transfected cells compared with control plasmid PsiRNA group and control group. Nucleolin at the protein level was significantly increased in the untransfected and control plasmid groups following Ang II stimulation, while the expression of nucleolin was significantly inhibited in PsiRNA-Nuc-transfected cells were treated with $10^{-6} \mathrm{mmol} / \mathrm{l}$ Ang II for $48 \mathrm{~h}$ compared with the other Nag II treated groups (Fig. 3C). Additionally, the expression of OPN was significantly increased in the untransfected and control plasmid groups after Ang II stimulation, while the expression of OPN was significantly inhibited in PsiRNA-Nuc-transfected cells treated with $10^{-6} \mathrm{mmol} / \mathrm{l}$ Ang II for $48 \mathrm{~h}$ compared with the other Ang II-treated groups. By contrast, the expressions of contractive phenotype markers $\alpha$-SM-actin, calponin and SM22a were significantly decreased in the untransfected and control plasmid groups following Ang II stimulation, while such downregulation was reduced in PsiRNA-Nuc-transfected cells treated with $10^{-6} \mathrm{mmol} / \mathrm{l}$ Ang II for $48 \mathrm{~h}$ by comparison (Fig. 3D).

Effects of nucleolin on Ang II-induced expression of phenotypic transformation-associated genes and the binding of nucleolin protein with tropoelastin, epiregulin, and fibroblast growth factor 2 (b-FGF) mRNA in VSMCs. Previous studies have demonstrated that the RBD in nucleolin can bind to the corresponding binding elements in target mRNAs, (T/G) CCCG (A/G). Subsequently, the mRNA stability of the target gene is modulated by nucleolin, mediating post-transcriptional regulation of certain genes. Therefore, mRNA sequences of phenotypic transformation-associated genes in VSMCs were screened by bioinformatics analysis, and multiple phenotypic transformation-associated genes containing nucleolin binding elements '(T/G) CCCG $(\mathrm{A} / \mathrm{G})$ ' were identified. Table II lists the mRNA sequences of 12 genes containing nucleolin binding elements, including epiregulin. The PsiRNA-Nuc interference vector and control plasmid PsiRNA were transiently transfected into VSMCs, and then cells were treated with $10^{-6} \mathrm{mmol} / \mathrm{l}$ Ang II for $48 \mathrm{~h}$. The results demonstrated that the expression of phenotypic transformation-associated genes, tropoelastin, epiregulin and b-FGF, were significantly increased in the untransfected and control plasmid groups following Ang II stimulation, while their expressions were significantly inhibited in PsiRNA-Nuc-transfected cells compared with the other Ang II stimulation groups (Fig. 4A). However, nucleolin overexpression further increased the Ang II-induced expressions of tropoelastin, epiregulin and b-FGF (Fig. 4A). 

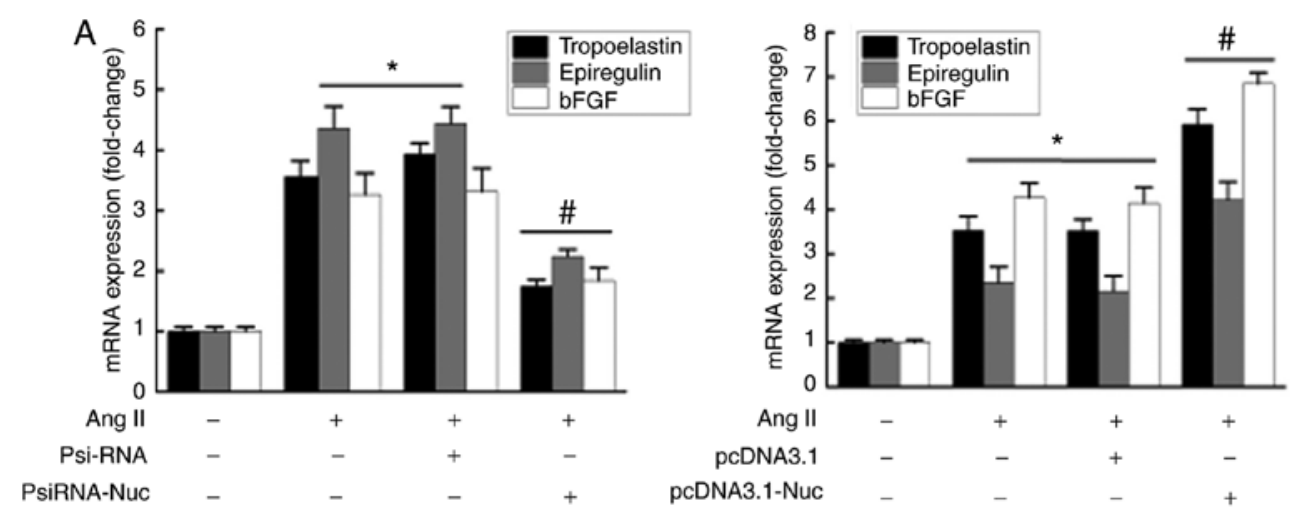

B
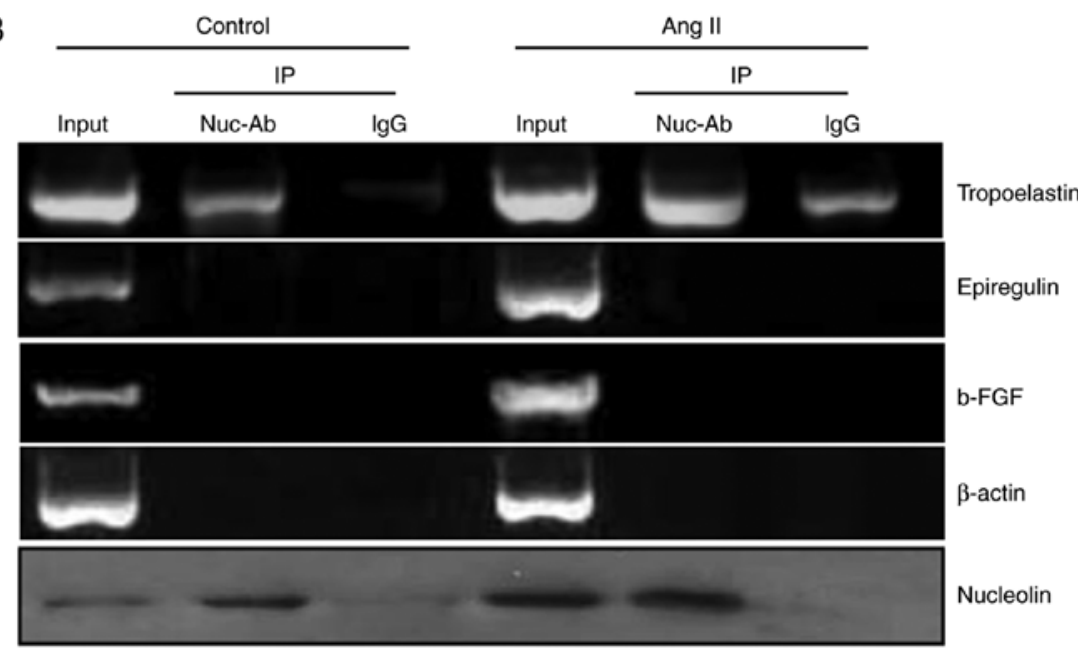

Figure 4. Effects of nucleolin on Ang II-induced expressions of phenotypic transformation-associated genes and the binding of nucleolin protein with tropoelastin, epiregulin and b-FGF mRNA in VSMCs. (A) Left, effects of silencing of nucleolin on Ang II-induced expressions of phenotypic transformationrelated genes tropoelastin, epiregulin and b-FGF in VSMCs. VSMCs were transfected with PsiRNA and PsiRNA-Nuc, the total RNA was extracted from the transfected cells after $48 \mathrm{~h}$, and then RT-qPCR was performed. Right, effect of nucleolin overexpression on Ang II-induced expressions of phenotypic transformation-associated genes tropoelastin, epiregulin and b-FGF in VSMCs. VSMCs were transfected with pcDNA3.1 and pcDNA3.1-Nuc, the total RNA was extracted from the transfected cells after $48 \mathrm{~h}$, and then the RT-qPCR was performed. Data are expressed as the mean \pm standard error, $\mathrm{n}=5$; ${ }^{*} \mathrm{P}<0.05$ vs. normal control group; ${ }^{\#} \mathrm{P}<0.05$ vs. untransfected cell group and pcDNA3.1 or PsiRNA group). (B) Normal VSMCs and Ang II-treated VSMCs were collected to prepare the cell extracts, cell extracts were divided into three equal groups: Input group, negative control IgG group and nucleolin antibody group. Immunoprecipitation was performed out using rabbit anti-nucleolin monoclonal antibody, and total mRNA was extracted from the sediment. Representative of three separate experiments. VSMCs, vascular smooth muscle cells; RT-qPCR, reverse transcription-quantitative polymerase chain reaction; Ang II, angiotensin II treatment; pcDNA3.1, control plasmid group; pcDNA3.1-Nuc, nucleolin overexpression plasmid; PsiRNA, control plasmid group; PsiRNA-Nuc, nucleolin RNA interference plasmid; Input, positive control; IgG, immunoglobulin G negative control; Nuc-Ab, nucleolin antibody; Ctrl, control cells; IP, immunoprecipitation; b-FGF, fibroblast growth factor 2 .

In order to identify the genes that interact with nucleolin during phenotypic transformation, protein-RNA co-immunoprecipitation and RT-qPCR were used. The results demonstrated that only a small amount of tropoelastin mRNA was precipitated in normal cell lysate. However, the amount of tropoelastin mRNA precipitated when using a nucleolin antibody was increased compared with the control IgG group, suggesting that nucleolin binds to tropoelastin mRNA. The amount of tropoelastin mRNA in cell lysates was increased by Ang II stimulation. However, the amount of tropoelastin mRNA precipitated by nucleolin antibody was also increased compared with the control $\operatorname{IgG}$ group, suggesting that the binding of nucleolin and tropoelastin mRNA was increased by Ang II stimulation. However, binding between nucleolin and epiregulin or b-FGF through was not observed by immunoprecipitation. In addition, $\beta$-actin was used as a control, and the findings revealed that the binding of nucleolin and tropoelastin mRNA was specific. Western blot analysis was used to detect the content of nucleolin in the cell extracts and the sediments, which confirmed the effectiveness of the nucleolin antibody pull down of nucleolin (Fig. 4B).

Effect of nucleolin on tropoelastin mRNA stability and tropoelastin protein expression in VSMCs. Following transfection with pcDNA3.1 and pcDNA3.1-Nuc for $48 \mathrm{~h}$, cells were treated with actinomycin $\mathrm{D}(5 \mu \mathrm{g} / \mathrm{ml})$, and the decay of tropoelastin mRNA was assayed. Compared with the control group, overexpression of nucleolin slowed the degradation of tropoelastin mRNA, indicating increased tropoelastin mRNA stability, However, the control plasmid had no significant effect on the tropoelastin mRNA stability (Fig. 5A). The effect of Ang II on the stability of tropoelastin mRNA was also analyzed. Compared with the control group, Ang II slowed the degradation of tropoelastin mRNA, indicating increased tropoelastin mRNA stability (Fig. 5B). VSMCs were transfected with nucleolin siRNA for $24 \mathrm{~h}$ before Ang II treatment, and the effect of 

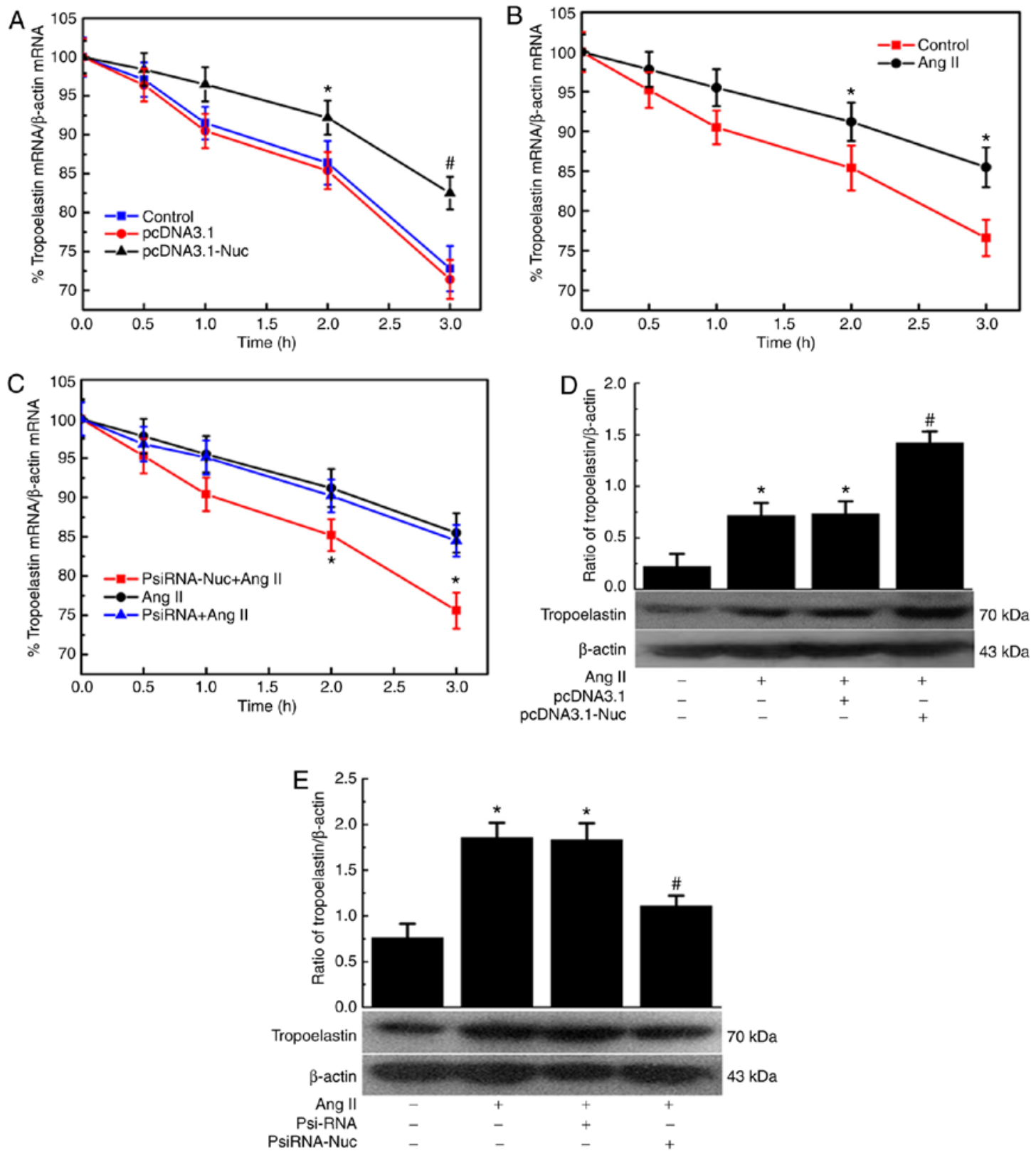

Figure 5. Effect of nucleolin on tropoelastin mRNA stability and tropoelastin protein expression in VSMCs. (A) Effect of nucleolin overexpression on tropoelastin mRNA stability in VSMCs. VSMCs were transfected with pcDNA3.1 and pcDNA3.1-Nuc for $48 \mathrm{~h}$, and then incubated with actinomycin D $(5 \mu \mathrm{g} / \mathrm{ml})$ for various periods of time $(0,0.5,1,2$ and $3 \mathrm{~h})$. The mRNA levels of tropoelastin were determined by RT-qPCR. ${ }^{\prime \prime} \mathrm{P}<0.05$ vs. Vect group, ${ }^{\prime \prime} \mathrm{P}<0.01 \mathrm{vs}$. Vect group, $\mathrm{n}=5$. (B) Effect of Ang II on tropoelastin mRNA stability in VSMCs. VSMCs were treated with $10^{-6} \mathrm{mM}$ Ang II for $48 \mathrm{~h}$. The cells were then incubated with actinomycin D $(5 \mu \mathrm{g} / \mathrm{ml})$ for various periods of time $(0,0.5,1,2$ and $3 \mathrm{~h})$. The mRNA levels of tropoelastin were determined by RT-qPCR. ${ }^{*} \mathrm{P}<0.05$ vs. Ctrl group, $n=5$. (C) Effect of low expression of nucleolin on tropoelastin mRNA stability in VSMCs. VSMCs were transfected with nucleolin siRNA plasmid for $24 \mathrm{~h}$, cells were treated with $10^{-6} \mathrm{mmol} / 1 \mathrm{Ang}$ II for $48 \mathrm{~h}$, and then incubated with actinomycin D $(5 \mu \mathrm{g} / \mathrm{ml})$ for various periods of time $(0,0.5$, 1,2 and $3 \mathrm{~h}$ ). The mRNA levels of tropoelastin were determined by RT-qPCR. "P<0.05 vs. PsiRNA group, $\mathrm{n}=5$. Effect of nucleolin (D) overexpression and (E) low expression on Ang II-induced expressions of tropoelastin. VSMCs were transfected with pcDNA3.1, pcDNA3.1-Nuc, PsiRNA and PsiRNA-Nuc, and then cells were treated with $10^{-6} \mathrm{mmol} / \mathrm{l}$ Ang II for $48 \mathrm{~h}$. Data are expressed as the mean \pm standard error, $\mathrm{n}=5 ;{ }^{*} \mathrm{P}<0.05$ vs. normal control group, ${ }^{*} \mathrm{P}<0.05$ vs. untransfected cell group and pcDNA3.1 group. VSMCs, vascular smooth muscle cells; RT-qPCR, reverse transcription-quantitative polymerase chain reaction; Ctrl, control; Vect, transfected with pcDNA3.1 plasmid; Nuc, transfected with pcDNA3.1-Nuc plasmid; Ang II, angiotensin II; PsiRNA, control plasmid group; psiRNA-Nuc, nucleolin RNA interference plasmid.

Ang II on tropoelastin mRNA stability was relieved. However, the control plasmid had no significant effect on the tropoelastin mRNA stability (Fig. 5C). The effect of nucleolin overexpression and silencing of nucleolin on the protein expression of tropoelastin was also assessed. The results demonstrated that the expression of tropoelastin was significantly increased in the untransfected and control plasmid groups following Ang II stimulation, while nucleolin overexpression further increased the Ang II-induced expression of tropoelastin (Fig. 5D). The expression of tropoelastin was significantly increased in the untransfected and control plasmid groups following Ang II stimulation, while the expression of tropoelastin was significantly inhibited in PsiRNA-Nuc-transfected cells treated with $10^{-6} \mathrm{mmol} / \mathrm{l}$ Ang II for $48 \mathrm{~h}$ (Fig. 5E). 


\section{Discussion}

Phenotypic transformation of VSMCs has a pivotal role in the pathogenesis of cardiovascular diseases, including hypertension, coronary artery disease and angiographic restenosis. Great efforts have been made to inhibit the phenotypic transformation of VSMCs, providing an important experimental and theoretical basis for the prevention and treatment of cardiovascular diseases. Measures to potentially prevent and treat cardiovascular diseases that have been investigated include the following: Gene transfection, RNA interference, blockade of transcription factors at the nuclear transcription level, certain drugs inhibiting the phenotypic transformation of VSMCs, and replacement, repair or enhancement of vascular endothelial function in damaged tissues or organs by stem cell transplantation $(3,21-24)$. Although great progress has been made to uncover the underlying mechanism of VSMC phenotypic transformation, the specific mechanisms has not been fully elucidated. Therefore, understanding the molecular mechanisms regulating VSMC phenotypic transformation has become a key measure to control the abnormal proliferation of VSMCs, and such efforts may also provide a novel theoretical approach for angioplasty of atherosclerotic disease, hypertension and angiographic restenosis.

Generally, it is believed that endogenous active substances in the body have a spontaneous regulatory role in the proliferation or phenotypic transformation of VSMCs. Therefore, to clarify the mechanism, a key step is to identify novel endogenous regulatory proteins mediating the phenotype of VSMCs. Although a variety of cytokines, growth factors and vasoactive substances are involved in phenotypic transformation of VSMCs (25-27), it remains unclear what type of factors have a key role in VSMC phenotypic transformation. Nucleolin (also known as C23) is the most abundant of 271 nucleolar proteins, accounting for $\sim 10 \%$ of the total nucleolar protein content. It has a fundamental role in the nucleolus of eukaryotic cells. Nucleolin is involved in the ribosome biosynthesis and maturation, cell proliferation, growth, embryogenesis, cytokinesis, chromatin replication and nucleolus function $(28,29)$. A large number of studies have demonstrated that nucleolin is highly expressed in proliferating tissues and cells, including stem cells and tumor cells, and it promotes the regeneration of stem cells and the growth of tumor cells $(12,30,31)$. The expression level of nucleolin is positively correlated with the rate of cell division, and remains at a fairly high level in tumor cells and other rapidly dividing cells (32). These results suggest that nucleolin may regulate the phenotypic transformation of VSMCs under pathological conditions, while it remains largely unexplored whether and how nucleolin regulates the phenotypic transformation of VSMCs.

In order to clarify the role of nucleolin in the phenotypic transformation of VSMCs, Ang II was used to induce the phenotypic transformation of VSMCs. The results of the current study demonstrated that the expressions of $\alpha$-SM-actin, SM22a and calponin at the mRNA and protein levels were gradually decreased by Ang II stimulation, while the expression of OPN mRNA and protein was gradually increased by Ang II stimulation. These results suggested that Ang II significantly promoted the phenotypic transformation of VSMCs. An increasing number of studies have reported that a variety of factors can alter the expression of nucleolin $(6-8,11,14)$. However, it is unknown whether the nucleolin expression is changed in cell models of VSMC phenotypic transformation induced by Ang II. RT-qPCR and western blot analysis demonstrated that the expression of nucleolin mRNA and protein was increased by treatment Ang II at different concentrations for $48 \mathrm{~h}$, and the most evident effect was observed when VSMCs were treated with $10^{-6} \mathrm{mmol} / \mathrm{l}$ Ang II for $48 \mathrm{~h}$. Furthermore, VSMCs were treated with $10^{-6} \mathrm{mmol} / \mathrm{l}$ Ang II for different durations, and the most evident effect was observed at $48 \mathrm{~h}$. Dose- and time-response experiments demonstrated that the proliferation of VSMCs was increased by Ang II in a dose-and time-dependent manner. This indicates that Ang II has no obvious cytotoxic effects on VSMC within $72 \mathrm{~h}$ or at $10^{-5} \mathrm{mmol} / \mathrm{l}$. Therefore, in order to avoid the toxic side effects of continuous drug stimulation on cells, we used time points of 12, 24, 48 and $72 \mathrm{~h}$ to observe the expression of nucleolin after Ang II stimulation. Based on the expression pattern of nucleolin, it was hypothesized that upregulation of nucleolin may have a role in Ang II-induced phenotypic transformation of VSMCs. However, the mechanism underlying the Ang II-induced upregulation of nucleolin remained unclear. It has been previously reported that the activation of the mitogen-activated protein kinase (MAPK) pathway can also upregulate the expression of nucleolin (33). Furthermore, Ang II-induced proliferation and phenotypic transformation of VSMCs have been associated with activation of extracellular signal-regulated kinase $1 / 2$, and activation of c-Jun N-terminal kinase, P38 MAPK and nuclear factor-KB (NF-KB) $(34,35)$. Therefore, Ang II may upregulate the expression of nucleolin by activating signaling pathways, such as MAPK and NF-KB. However, this hypothesis should be further validated.

It was also observed that in normal untreated and untransfected cells, the majority of the nucleolin was localized in the nucleus of VSMCs, and Ang II induced the translocation of nucleolin from the nucleus to cytoplasm. These results suggested that nucleolin had a role in the phenotypic transformation of VSMCs induced by Ang II, and such role may depend on its cytoplasmic localization. Studies have reported that the translocation of nucleolin to the cytoplasm depends on the phosphorylation of an amino-terminal threonine induced by cdc2 kinase, whereas dephosphorylation promotes its translocation to the nucleus (36). Therefore, Ang II may have a role in regulating VSMC phenotypic transformation by activating certain kinases, leading to the translocation of nucleolin. To investigate the role of nucleolin in the phenotypic transformation of VSMCs, rat VSMCs were transfected with the recombinant plasmid pcDNA3.1-Nuc and control plasmid pcDNA3.1. Results showed that overexpression of nucleolin promoted the VSMC phenotypic transformation induced by Ang II. Similarly, we further examined the effect of low expression of nucleolin on Ang II-induced phenotypic transformation of VSMCs, and revealed that downregulation of nucleolin suppressed the promotion of phenotypic transformation. These findings, for the first time, demonstrated that the upregulation of nucleolin played a key role in the phenotypic transformation of VSMCs induced by Ang II. However, the mechanism of action of nucleolin remains unclear.

It has been reported that the CS-RBD, which binds the consensus sequence $(\mathrm{T} / \mathrm{G}) \mathrm{CCCG}(\mathrm{A} / \mathrm{G})$, is structurally crucial 
for the role of RNA-binding proteins in primary transcript splicing and maturational regulation of ribosomal RNA (10-15). In addition, a large number of studies have reported that this structural domain also mediates the post-transcriptional regulation of certain genes by nucleolin $(10,11,13,14,29,37,38)$. For example, the binding of nucleolin to the 5' UTR of interleukin (IL)-2 and growth arrest and DNA-damage-inducible $\alpha$ mRNA coding region modulates the protein expressions of target genes by regulating the stability of these target mRNAs $(37,38)$. The RBD of nucleolin can bind to the 5 ' and 3' UTRs of mRNAs of Bcl-2, protein kinase B, p53 and other apoptosis-associated genes, with a crucial role in promoting cell proliferation and anti-apoptotic effect $(10,11,13)$. Nucleolin regulates the nuclear and nucleolar localization of telomerase by binding to the telomerase RNA component human telomerase reverse transcriptase through four RBDs, thus mediating cell growth and proliferation (14). Previous studies have also demonstrated that nucleolin enhances the stability of ATP binding cassette subfamily A member $1 \mathrm{mRNA}$, subsequently increasing cholesterol efflux and inhibiting the formation of foam cells (29). These studies have suggested that the RNA binding is the key step for nucleolin to regulate various biological functions, such as cell growth and proliferation.

The current study demonstrated that nucleolin may have a positive modulating effect on the phenotypic transformation of VSMCs, and its underlying mechanism may be through regulating the expressions of certain phenotypic transformation-associated genes in VSMCs. However, it remained largely unexplored how nucleolin regulated the expressions of these genes. Furthermore, it also remained unclear whether nucleolin, as an RNA binding protein, regulated its stability and expression through interacting with mRNAs associated with phenotypic transformation, and thus, a role in the phenotypic transformation of VSMCs-induced by Ang II. The mRNA sequences of phenotypic transformation-associated genes in VSMCs were analyzed in bioinformatics analysis. Multiple phenotypic transformation-associated genes containing the nucleolin binding element were identified. Additionally, in order to investigate whether nucleolin can upregulate expression by binding to mRNAs containing the nucleolin binding element, such as tropoelastin, epiregulin and b-FGF, the effects of overexpression and silencing of nucleolin on the expressions of phenotypic transformation-associated genes were investigated. The findings revealed that overexpression of nucleolin promoted the expressions of tropoelastin, epiregulin and b-FGF, while silencing of nucleolin significantly downregulated the expressions of these genes. These findings suggested that the expressions of tropoelastin, epiregulin and b-FGF were regulated by nucleolin. Protein-RNA co-precipitation indicated that there was an interaction between tropoelastin mRNA and nucleolin protein, promoting the stability of tropoelastin mRNA and enhancing the expression of tropoelastin at the protein level. mRNA stability is mainly regulated by cis-acting elements and the trans-acting factors. Cis-acting elements are part of the structure of the mRNA itself, including sequences in the 3' UTR, 5' UTR and coding region. Trans-acting factors are proteins that bind to cis-acting elements. Whether RNA binding protein nucleolin can bind to the 3' UTR, 5' UTR or coding region of tropoelastin mRNA to regulate mRNA stability requires further investigation.
Therefore, it is necessary to demonstrate the interaction between nucleolin and tropoelastin or other genes and its specific mechanisms from multiple perspectives. For example, luciferase reporter gene, RNA-electrophoretic mobility shift assay and other techniques can be used to further examine the presence of mutual binding and stability of target mRNAs following binding.

It is established that the phenotypic transformation of VSMCs is affected and regulated by a variety of growth factors (epidermal growth factor, b-FGF, vascular endothelial growth factor, platelet-derived growth factor, nerve growth factor), cytokines (transforming growth factor, IL-1, IL-6, tumor necrosis factor- $\alpha$ ), vasoactive substances (Ang II, nitric oxide, prostacyclin) and extracellular matrix proteins (39-41). When VSMCs undergo phenotypic transformation, the expressions of synthetic markers, including OPN, epiregulin, tropoelastin and thrombospondin, are upregulated in VSMCs (42). In the present study, it was preliminarily confirmed that nucleolin has an important role in the phenotypic transformation of VSMCs induced by Ang II, and nucleolin in combination with tropoelastin mRNA exerted a positive effect on phenotypic transformation. However, the association between nucleolin and other phenotypic transformation-associated genes remain unclear. In addition, nucleolin is a multifunctional protein. Besides binding to RNA, nucleolin can also bind to DNA (similar to transcription factors) to regulate the gene transcription by interacting with the gene promoter region. Further studies are required explore whether nucleolin can interact with the promoters of tropoelastin or other associated genes and regulate the phenotypic transformation of VSMCs at the transcriptional level. The phenotypic transformation of VSMCs is extremely complex, and the current study provided a new perspective for the investigation of the regulatory mechanism of VSMC phenotypic transformation. Nucleolin may mediate the post-transcriptional regulation of VSMC phenotypic transformation-associated mRNAs, affect the stability and protein expression of associated genes, and have a role in promoting phenotypic transformation. Therefore, nucleolin could be used as a target for the treatment of hypertension, atherosclerosis and angiographic restenosis. However, various contradictions require in depth investigation, such as if the expression of nucleolin is inhibited in VSMCs, phenotypic transformation may be inhibited, but the physiological regulation of nucleolin will be lost in normal VSMCs. Furthermore, it may have abnormal effects on the physiological function of cells. Therefore, how to control the balance between the inhibition of VSMC phenotypic transformation and the possible side effects of targeting nucleolin needs to be further investigated.

\section{Acknowledgements}

Not applicable.

\section{Funding}

This study was supported by the Fund from Bureau of Science and Technology of Changsha, China (grant no. Kq1701007) and Hunan Natural Science Foundation, China (grant no. 2018JJ6127). 


\section{Availability of data and materials}

All data generated or analyzed during this study are included in this published article.

\section{Authors' contributions}

All authors contributed extensively to the work presented in this paper. LF performed the experiments, analyzed statistical data, and wrote and revised the manuscript. ZXY designed the current study, acquired data, analyzed and interpreted the data. KKW provided the plasmids required for the experiment. KKW and PFZ participated in the design, analyzed the data and revised the manuscript. ZLX and MY acquired and analyzed the data. All authors read and approved the final manuscript.

\section{Ethics approval and consent to participate}

Not applicable.

\section{Patient consent for publication}

Not applicable.

\section{Competing interests}

The authors declare that they have no competing interests.

\section{References}

1. Rzucidlo EM, Martin KA and Powell RJ: Regulation of vascular smooth muscle cell differentiation. J Vasc Surg 45 (Suppl A): A25-A32, 2007.

2. Dong N, Wang W, Tian J, Xie Z, Lv B, Dai J, Jiang R, Huang D, Fang S, Tian J, et al: MicroRNA-182 prevents vascular smooth muscle cell dedifferentiation via FGF9/PDGFR $\beta$ signaling. Int J Mol Med 39: 791-798, 2017.

3. Shi N and Chen SY: Smooth muscle cell differentiation: Model systems, regulatory mechanisms, and vascular diseases. J Cell Physiol 231: 777-787, 2016.

4. Owens GK: Molecular control of vascular smooth muscle cell differentiation and phenotypic plasticity. Novart Found Symp 283: 174-191, 2007.

5. Chen $\mathrm{Z}$ and $\mathrm{Xu} \mathrm{X}$ : Roles of nucleolin. Focus on cancer and anti-cancer therapy. Saudi Med J 37: 1312-1318, 2016.

6. Jiang B, Zhang B, Liang P, Song J, Deng H, Tu Z, Deng G and Xiao X: Nucleolin/C23 mediates the antiapoptotic effect of heat shock protein 70 during oxidative stress. FEBS J 277: 642-652, 2010

7. Fang L, Wang KK, Jiang L, Jiang BM, Wei X, Song L, Deng GH and Xiao XZ: Role of cell-surface nucleolin in lipopolysaccharide-stimulated expression and secretion of TNF-alpha and IL-1beta. Zhong Nan Da Xue Xue Bao Yi Xue Ban 33: 999-1004, 2008 (In Chinese).

8. Huang F, Wu Y, Tan H, Guo T, Zhang K, Li D and Tong Z. Phosphorylation of nucleolin is indispensable to its involvement in the proliferation and migration of non-small cell lung cancer cells. Oncol Rep 41: 590-598, 2019.

9. Wang Y, Mao M and Xu JC: Cell-surface nucleolin is involved in lipopolysaccharide internalization and signalling in alveolar macrophages. Cell Biol Int 35: 677-685, 2011.

10. Iliakis G, Krieg T, Guan J, Wang Y and Leeper D: Evidence for an S-phase checkpoint regulating DNA replication after heat shock: A review. Int J Hyperthermia 20: 240-249, 2004.

11. Huang Y, Shi H, Zhou H, Song X, Yuan S and Luo Y: The angiogenic function of nucleolin is mediated by vascular endothelial growth factor and nonmuscle myosin. Blood 107: 3564-3571, 2006.

12. Cheng Y, Zhao G, Zhang S, Nigim F, Zhou G, Yu Z, Song Y, Chen Y and Li Y: AS1411-induced growth inhibition of glioma cells by up-regulation of p53 and down-regulation of Bcl-2 and Akt1 via nucleolin. PLoS One 11: e0167094, 2016.
13. Fu Y, Chen Y, Luo X, Liang Y, Shi H, Gao L, Zhan S, Zhou D and Luo Y: The heparin binding motif of endostatin mediates its interaction with receptor nucleolin. Biochemistry 48: 11655-11663, 2009.

14. Wang K, Deng G, Chen G, Liu M, Yi Y, Yang T, McMillan DR and Xiao X: Heat shock protein 70 inhibits hydrogen peroxide-induced nucleolar fragmentation via suppressing cleavage and down-regulation of nucleolin. Cell Stress Chaperon 17: 121-130, 2012.

15. Khurts S, Masutomi K, Delgermaa L, Arai K, Oishi N, Mizuno H, Hayashi N, Hahn WC and Murakami S: Nucleolin interacts with telomerase. J Biol Chem 279: 51508-51515, 2004.

16. Jiang B, Liang P, Wang K, Lv C, Sun L, Tong Z, Liu Y and Xiao X: Nucleolin involved in myocardial ischaemic preconditioning via post-transcriptional control of HSPA1A expression. Cardiovasc Res 102: 56-67, 2014.

17. Tulchin N, Chambon M, Juan G, Dikman S, Strauchen J, Ornstein L, Billack B, Woods NT and Monteiro AN: BRCA1 protein and nucleolin colocalize in breast carcinoma tissue and cancer cell lines. Am J Pathol 176: 1203-1214, 2010.

18. Mosafer J and Mokhtarzadeh A: Cell surface nucleolin as a promising receptor for effective AS1411 aptamer-mediated targeted drug delivery into cancer cells. Curr Drug Deliv 15: 1323-1329, 2018.

19. Kimes BW and Brandt BL: Characterization of two putative smooth muscle cell lines from rat thoracic aorta. Exp Cell Res 98: 349-366, 1976.

20. Livak KJ and Schmittgen TD: Analysis of relative gene expression data using real-time quantitative PCR and the 2(-Delta Delta C(T)) method. Methods 25: 402-408, 2001.

21. Tuan NQ, Lee DH, Oh J, Kim CS, Heo KS, Myung CS and $\mathrm{Na}$ M: Inhibition of proliferation of vascular smooth muscle cells by cucurbitanes from momordica charantia. J Nat Prod 80: 2018-2025, 2017.

22. Tang Y, Yu S, Liu Y, Zhang J, Han L and Xu Z: MicroRNA-124 control human vascular smooth muscle cell phenotypic switch via Sp1. Am J Physiol Heart Circ Physiol 31: H641-H649, 2017.

23. Davis-Dusenbery BN, Wu C and Hata A: Micromanaging vascular smooth muscle cell differentiation and phenotypic modulation. Arterioscler Thromb Vasc Biol 31: 2370-2377, 2011.

24. Ma X, Jiang C, Li Y, Feng L, Liu J and Wang J: Inhibition effect of tacrolimus and platelet-derived grow th factor-BB on restenosis after vascular intimal injury. Biomed Pharmacother 93: 180-189, 2017.

25. Fang L, Chen MF, Xiao ZL, Liu Y, Yu GL, Chen XB and Xie XM: Calcitonin gene-related peptide released from endothelial progenitor cell inhibits the proliferation of rat vascular smooth muscle cells induced by angiotensin II. Mol Cell Biochem 355: 99-108, 2011.

26. Fang L, Chen MF, Xiao ZL, Yu GL, Chen XB and Xie XM: The effect of endothelial progenitor cells on angiotensin II-induced proliferation of cultured rat vascular smooth muscle cells. J Cardiovasc Pharmacol 58: 617-625, 2011.

27. Zhang MJ, Zhou Y, Chen L, Wang YQ, Wang X, Pi Y, Gao CY, Li JC and Zhang LL: An overview of potential molecular mechanisms involved in VSMC phenotypic modulation. Histochem Cell Biol 145: 119-130, 2016.

28. Andersen JS, Lyon CE, Fox AH, Leung AK, Lam YW, Steen H, Mann M and Lamond AI: Directed proteomic analysis of the human nucleolus. Curr Biol 12: 1-11, 2002.

29. Huang S: Building an efficient factory: Where is pre-rRNA synthesized in the nucleolus? J Cell Biol 157: 739-741, 2002.

30. Li Y, Jiang B, Liang P, Tong Z, Liu M, Lv Q, Liu Y, Liu X, Tang Y and Xiao X: Nucleolin protects macrophages from oxLDL-induced foam cell formation through up-regulating ABCA1 expression. Biochem Biophys Res Commun 486: 364-371, 2017.

31. Bose S, Tholanikunnel TE, Reuben A, Tholanikunnel BG and Spicer EK: Regulation of nucleolin expression by miR-194, miR-206, and HuR. Mol Cell Biochem 417: 141-153, 2016.

32. Galande S: Chromatin (dis)organization and cancer: BUR-binding proteins as biomarkers for cancer. Curr Cancer Drug Targets 2: 157-190, 2002.

33. Reyes-Reyes EM and Akiyama SK: Cell-surface nucleolin is a signal transducing P-selectin binding protein for human colon carcinoma cells. Exp Cell Res 314: 2212-2223, 2008

34. Chen T, Deng S and Lin R: The inhibitory effect of Isoliquiritigenin on the proliferation of human arterial smooth muscle cell. BMC Pharmacol Toxicol 18: 57, 2017.

35. Yu XH, Zheng XL and Tang CK: Nuclear Factor- $\kappa B$ activation as a pathological mechanism of lipid metabolism and atherosclerosis. Adv Clin Chem 70: 1-30, 2015. 
36. Webster KA, Discher DJ and Bishopric NH: Cardioprotection in an in vitro model of hypoxic preconditioning. J Mol Cell Cardiol 27: 453-458, 1995.

37. Chen CY, Gherzi R, Andersen JS, Gaietta G, Jürchott K, Royer HD, Mann M and Karin M: Nucleolin and YB-1 are required for JNK-mediated interleukin-2 mRNA stabilization during T-cell activation. Genes Dev 14: 1236-1248, 2000.

38. Zhang Y, Bhatia D, Xia H, Castranova V, Shi X and Chen F: Nucleolin links to arsenic-induced stabilization of GADD45alpha mRNA. Nucleic Acids Res 34: 485-495, 2006.

39. Izawa Y, Yoshizumi M, Ishizawa K, Fujita Y, Kondo S, Kagami S, Kawazoe K, Tsuchiya K, Tomita S and Tamaki T: Big mitogen-activated protein kinase 1 (BMK1)/extracellular signal regulated kinase 5 (ERK5) is involved in platelet-derived growth factor(PDGF)-induced vascular smooth muscle cell migration. Hypertens Res 30: 1107-1117, 2007.

40. Montezano AC, Callera GE, Yogi A, He Y, Tostes RC, He G, Schiffrin EL and Touyz RM: Aldosterone and Angiotensin II synergistically stimulate migration in vascular smooth muscle cells through c-Src-regulated redox-sensitive RhoA pathways. Arterioscler Thromb Vasc Biol 28: 1511-1518, 2008.
41. Wang S, Liu Y, Fan F, Yan J, Wang X and Chen J: Inhibitory effects of emodin on the proliferation of cultured rat vascular smooth muscle cell-induced by angiotensin II. Phytother Res 22: 247-251, 2008

42. Takahashi M, Hayashi K, Yoshida K, Ohkawa Y, Komurasaki T, Kitabatake A, Ogawa A, Nishida W, Yano M, Monden M and Sobue K: Epiregulin as a major autocrine/paracrine factor released from ERK- and p38MAPK-activated vascular smooth muscle cells. Circulation 108: 2524-2529, 2003.

This work is licensed under a Creative Commons Attribution-NonCommercial-NoDerivatives 4.0 International (CC BY-NC-ND 4.0) License. 